\title{
A systematic review and meta-analysis of the utility of EUS for preoperative staging for gastric cancer
}

\author{
Roberta Cardoso $\cdot$ Natalie Coburn $\cdot$ Rajini Seevaratnam • \\ Rinku Sutradhar · Laercio Gomes Lourenco • Alyson Mahar • \\ Calvin Law $\cdot$ Elaine Yong $\cdot$ Jill Tinmouth
}

Received: 28 March 2011/ Accepted: 31 October 2011/Published online: 12 January 2012

(C) The International Gastric Cancer Association and The Japanese Gastric Cancer Association 2011

\begin{abstract}
Background Accurate preoperative staging is important in determining the appropriate treatment of gastric cancer. Recently, endoscopic ultrasound (EUS) has been introduced as a staging modality. However, reported test characteristics for EUS in gastric cancer vary. Our purpose in this study was to identify, synthesize, and evaluate findings from all articles on the performance of EUS in the preoperative staging of gastric cancer.

Methods Electronic literature searches were conducted using Medline, Embase, and the Cochrane Central Register of Controlled Trials from 1 January 1998 to 1 December 2009. All search titles and abstracts were independently rated for relevance by a minimum of two reviewers. Meta-
\end{abstract}

Electronic supplementary material The online version of this article (doi:10.1007/s10120-011-0115-4) contains supplementary material, which is available to authorized users.

R. Cardoso · N. Coburn $(\bowtie) \cdot$ R. Seevaratnam · A. Mahar

Sunnybrook Research Institute,

Sunnybrook Health Sciences Centre, Toronto, Canada

e-mail: natalie.coburn@sunnybrook.ca

N. Coburn · C. Law

Division of Surgical Oncology, Sunnybrook Health Sciences

Centre and Odette Cancer Centre, Suite T2-60,

2075 Bayview Ave, Toronto, ON M4N 3M5, Canada

N. Coburn · R. Sutradhar $\cdot$ C. Law $\cdot$ J. Tinmouth

Institute for Clinical Evaluative Sciences, Toronto, Canada

L. G. Lourenco

Department of Surgery, Federal University of Sao Paulo,

Sao Paulo, Brazil

E. Yong $\cdot$ J. Tinmouth

Division of Gastroenterology, Department of Medicine,

Sunnybrook Health Sciences Centre, Toronto, Canada analysis for the performance of EUS was analyzed by calculating agreement (Kappa statistic), and pooled estimates of accuracy, sensitivity, and specificity for all EUS examinations, using histopathology as the reference standard. Subgroup analyses were also performed.

Results Twenty-two articles met our inclusion criteria and were included in the review. EUS pooled accuracy for $\mathrm{T}$ staging was $75 \%$ with a moderate Kappa (0.52). EUS was most accurate for $\mathrm{T} 3$ disease, followed by $\mathrm{T} 4, \mathrm{~T} 1$, and T2. EUS pooled accuracy for $\mathrm{N}$ staging was $64 \%$, sensitivity was $74 \%$, and specificity was $80 \%$. There was significant heterogeneity between the included studies. Subgroup analyses found that annual EUS volume was not associated with EUS T and $\mathrm{N}$ staging accuracy $(P=0.836$, 0.99 , respectively).

Conclusion EUS is a moderately accurate technique that seems to describe advanced T stage (T3 and T4) better than $\mathrm{N}$ or less advanced $\mathrm{T}$ stage. Stratifying by EUS annual volume did not affect EUS performance in staging gastric cancer.

Keywords Gastric cancer - Preoperative diagnosis . TNM staging $\cdot$ EUS $\cdot$ Meta-analysis

\section{Introduction}

Gastric cancer has a very poor prognosis. The outcomes of patients with gastric cancer are determined by histopathologic factors, such as depth of invasion, nodal status, and distant metastases [1]. Optimal treatment of patients with gastric cancer depends on accurately staging the cancer, and is most commonly accomplished through computed tomography (CT). Recently, endoscopic ultrasound (EUS) has been endorsed for the preoperative staging of gastric 
cancer by several groups, such as the National Comprehensive Cancer Network, the Brazilian Society of Gastrointestinal Endoscopy, and the Scottish Intercollegiate Guidelines Network [2-4].

\section{Endoscopic ultrasound}

Endoscopic ultrasound (EUS) was introduced into clinical practice in the early 1980s as a way to assess the extent of local tumor infiltration and local lymph node status [5-7]. The main advantage of EUS is the ability to place the transducer close to the lesion without interference of fat, bowel gas, or bone [6]. EUS allows evaluation of the individual layers of the gastric wall, as well as the identification of enlarged regional lymph nodes and metastasis in the liver; thus, it may be used to stage gastric cancer according to the TNM classification [1,8]. In particular, EUS is used to determine whether patients with early cancers are appropriate candidates for endoscopic mucosal resection [9]. Furthermore, EUS may also be helpful in planning the appropriate treatment strategy in patients with advanced gastric cancer (AGC), such as determining which patients are suitable for neoadjuvant chemotherapy or a multivisceral resection. To date, EUS imaging can be performed with echoendoscopes or with the use of ultrasound catheters or 'miniature probes' which are passed through standard endoscopes. These miniature probes can provide ultra-high-frequency imaging (12-30 MHz), compared to echoendoscopes (5-12 MHz). Higher frequency yields higher resolution of the tumor at the expense of depth of penetration, thus limiting nodal examination [1, 2]; thus, a higher frequency probe may provide better evaluation of a $\mathrm{T} 1 / \mathrm{T} 2$ cancer, while a lower frequency probe may be more accurate in predicting nodal involvement.

Unfortunately, EUS also presents some disadvantages. It is one of the most demanding endoscopic procedures and thus is highly operator-dependent. Extensive training and experience in the use of the echoendoscope are required to obtain complete and accurate images [10]. It cannot be performed adequately when the endoscope cannot be well positioned because of the tumor location, or when the full extent of the tumor cannot be visualized because of highgrade strictures [6]. Although EUS is well suited for the evaluation of local invasion, it is of limited usefulness in the overall assessment of more distant spread [6]. Furthermore, EUS is an invasive technique requiring sedation and has recognized procedure- and sedation-related complications, including mortality [6]. Lastly, EUS adds incremental costs, and therefore should be used only if it contributes significantly to improved patient management and outcomes [11].

Several studies have compared the preoperative endosonographic assessment of $\mathrm{T}$ and $\mathrm{N}$ stage with histopathological staging of the resected specimen. However, the results from these studies vary considerably. Therefore, the goals of this meta-analysis were to: (1) comprehensively identify, synthesize, and evaluate findings from articles on the accuracy of EUS in the preoperative staging of gastric cancer; (2) determine EUS accuracy for different $\mathrm{T}$ stages (T1, T2, T3, and T4); and (3) verify EUS sensitivity and specificity for $\mathrm{N}$ staging.

\section{Methods}

\section{Data sources}

Electronic literature searches were conducted using Medline and Embase from 1 January 1998 to 1 December 2009 according to the search algorithm presented in Appendix A. Search terms included: [exp Stomach Cancer/or (( (gastric or stomach) adj1 cancer\$) or ((gastric or stomach) adj1 carcinoma) or ((gastric or stomach) adj1 adenocarcinoma) or ((gastric or stomach) adj1 neoplasm\$)).mp.] and [exp gastrointestinal endoscopy/or esophagogastroduodenoscopy/or endoscopy/or digestive tract endoscopy/or ESOPHAGOSCOPY/or cancer staging/or exp endoscopic therapy/or exp endoscopic surgery/or endoscopic mucosal resection/or endoscopic echography/or "endoscopic ultrasound".mp. or endoscopic echography/] and [human and English language] and [clinical trial/or controlled clinical trial/or exp comparative study/or meta-analysis/or multicenter study/or exp practice guideline/or randomized controlled trial/] not [*gastrointestinal stromal tumor/] or [exp B cell lymphoma/and "marginal zone".mp.] not [case report/or review]. A separate search of the Cochrane Central Register of Controlled Trials (1998-2009) was performed using the search term "gastric cancer". No attempt was made to locate unpublished material or contact researchers for unpublished studies.

\section{Study selection and review process}

To be eligible, studies had to meet the following criteria: (1) the diagnostic/staging accuracy of EUS in patients with histologically proven gastric cancer was investigated, (2) studies involving only patients submitted to a gastrectomy, (3) no age or gender restrictions, (4) publication in a peerreviewed journal from 1 January 1998 to 1 December 2009, and (5) publication in English. We excluded (1) reviews, meta-analyses, systematic reviews, abstracts, editorials or letters, case reports, and guidelines; (2) studies involving fewer than 30 patients; (3) studies evaluating mixed cancers with combined data analysis; (4) studies that did not provide sufficient information to determine at least one of the preoperative staging performance measures (accuracy, sensitivity, or specificity); (5) animal and ex vivo studies; 
(6) studies in which patients were presurgically treated with radiotherapy or chemotherapy; and (7) studies that did not use the TNM classification system.

All electronic search titles, selected abstracts, and fulltext articles were independently assessed by a minimum of two reviewers (NC, JT, or RC). Reference lists from review papers and relevant articles were also examined for additional studies that met our inclusion criteria. Disagreements on study inclusion/exclusion were resolved with a consensus meeting.

\section{Data extraction}

A systematic approach to data extraction was used to produce a descriptive summary of participants, interventions, and study findings (Table 1). The first reviewer (RC) independently extracted the data and a second reviewer (NC or JT) reviewed the data extraction. Only data on patients who underwent a preoperative EUS assessment and subsequent surgery with pathologic examination were extracted. In this review, if a selected article presented or compared EUS performance with the performance of another procedure on gastric cancer staging (e.g., CT, magnetic resonance imaging [MRI]) only the results related to EUS performance were considered for analysis. No attempt was made to contact authors for additional information.

\section{Quality of studies}

A number of criteria and tools to assess quality of studies have been developed [12-14]. However, there is a lack of consensus on how to best assess the quality of non-randomized clinical trials $[1,15]$. Consequently, for this metaanalysis, studies were selected based on completeness of data and inclusion criteria only [1].

\section{Data analysis}

Descriptive characteristics were collected for each included study. A wide range of definitions was found for the calculation of accuracy, sensitivity, and specificity. Therefore, the following performance characteristics were re-calculated from the original numbers provided in each included publication: accuracy, agreement (Kappa statistic), sensitivity, and specificity. Accuracy was defined as the proportion of tumors where staging using EUS agreed with the postoperative staging using histopathology. We constructed $4 \times 4$ tables for $\mathrm{T}$ stage (corresponding to T1, T2, T3, and T4) or $5 \times 5$ tables when the preoperative imaging technique did not detect the presence of a tumor (T0). Similarly, we created $2 \times 2$ tables for preoperative $\mathrm{N}$ staging (corresponding to N0 and $\mathrm{N}+$ ). Using these tables, we calculated agreement between EUS technique and pathology for $\mathrm{T}$ and $\mathrm{N}$ assessment using the Kappa statistic [16]. Also, using the tables for preoperative $\mathrm{N}$ staging, we calculated the sensitivity and specificity of lymph node staging.

The meta-analyses were calculated using the inverse variance method; $95 \%$ confidence intervals (CIs) were calculated for the pooled estimates of the accuracy, Kappa statistic, sensitivity, and specificity. Non-overlapping 95\% CIs were used to determine a significant difference between groups [16]. The following interpretation of Kappa was used: $<0=$ less than chance agreement, $0.01-0.20=$ slight agreement, $0.21-0.40=$ fair agreement, $0.41-0.60=$ moderate agreement, $\quad 0.61-0.80=$ substantial agreement, 0.81-0.99 = almost perfect agreement [16].

$I^{2}$ and Cochran's $Q$ tests were performed to assess the heterogeneity between studies (for the Cochran $Q$ test, heterogeneity was present if $P<0.05$, while values of $I^{2}$ to 25, 50, and $75 \%$ represented low, moderate, and high heterogeneity, respectively). As significant heterogeneity was identified, the EUS annual volume was investigated as a potential cause. We calculated annual volume by dividing the total number of cases by the number of reported years of study. Studies were grouped by annual volume and according to accuracy; $2 \times 2$ tables were constructed. For annual volume, we stratified centers into those that performed more than, and those that performed less than, 30 EUS procedures per year. For the pooled accuracy of T and $\mathrm{N}$ staging, we divided centers into those with EUS accuracy higher than $70 \%$ and those with accuracy lower than $70 \%$. We also aimed to explore the transducer frequency as a source of heterogeneity by investigating the diagnostic accuracy in different stages according to the type of transducer frequency. We attempted to divide studies into those that used a higher-frequency transducer $(>12 \mathrm{MHz})$ and those that used a lower-frequency transducer ( $\leq 12 \mathrm{MHz}$ ) to compare the EUS accuracy (EUS accuracy higher than $70 \%$ and lower than $70 \%$ ) for all T staging. Six studies used a combination of both low- and high-frequency transducers (as shown in Table 1). Unfortunately, these studies did not clearly report when the low- or highfrequency transducers were used; as a result they were excluded. No studies exclusively used high-frequency transducers. Consequently, it was possible to identify only one group of studies $(\leq 12 \mathrm{MHz})$. Therefore, it was not feasible to create comparison groups.

Statistical analyses were performed using the $\mathrm{R}$ version 2.10.1 statistical package (The R Foundation for Statistical Computing, ISBN 3-900051-07-0, http://cran.r-project.org/).

\section{Results}

A total of 7117 titles were identified from the electronic and hand searches for preliminary review. After removal of 
Table 1 Characteristics of included studies

\begin{tabular}{|c|c|c|c|c|c|}
\hline Author & Country & Study type & $N$ & Instrumentation used & Frequency of probe \\
\hline Ahn [17] & Korea & $\mathrm{P}$ & 71 & Radial array & 5 and $12 \mathrm{MHz}$ \\
\hline Akahoshi [18] & Japan & $\mathrm{P}$ & 78 & $\begin{array}{l}\text { (1) Ultrathin mechanical radial scanning probe with a } 2.6-\mathrm{mm} \\
\text { probe, (2) electronic endoscopes EVG-CT (Fujinon) or GIF-Q200 } \\
\text { (Olympus) }\end{array}$ & (1) $15 \mathrm{MHz}$, (2) NR \\
\hline Ang [7] & Singapore & $\mathrm{P}$ & 57 & Radial EES—GF UM20 (Olympus) & 7.5-12 MHz \\
\hline Barbour [19] & Japan & $\mathrm{R}$ & 209 & $\begin{array}{l}\text { GF-UM3 (Olympus), GF-UM130 (Olympus) or MH-908 radial } \\
\text { scanning EES (Olympus) }\end{array}$ & 7.5 and $12 \mathrm{MHz}$ \\
\hline Bentren [20] & USA & $\mathrm{R}$ & 225 & Transducer from the Olympus Corporation ${ }^{\mathrm{a}}$ & $7.5-12 \mathrm{MHz}$ \\
\hline Bhandari [21] & Korea & $\mathrm{P}$ & 63 & $\begin{array}{l}\text { UM-2R/3R (Olympus) and GF-UMQ } 200 \text { radial scanning EES } \\
\text { (Olympus) }\end{array}$ & 7.5-20 MHz \\
\hline Chen [22] & Taiwan & $\mathrm{R}$ & 57 & $45^{\circ}$ oblique viewing EES-GF-UM 20 (Olympus) & 7.5-12 MHz \\
\hline Ganpathi [23] & Singapore & $\mathrm{R}$ & 102 & Radial EES—GF-UM20 (Olympus) & 7.5 or $12 \mathrm{MHz}$ \\
\hline Habermman [24] & Germany & $\mathrm{P}$ & 51 & Radial EES—GF UM2, GF-UM3 (Olympus) & 7.5 or $12 \mathrm{MHz}$ \\
\hline Hizawa [25] & Japan & $\mathrm{P}$ & 226 & $\begin{array}{l}\text { GF-UM conventional radial-sector transducers, GF-UM20 } \\
\text { miniature probe system, UM-2R and UM-3R (all Olympus) }\end{array}$ & $12-20 \mathrm{MHz}$ \\
\hline Javaid [26] & India & $\mathrm{NC}$ & 112 & GF-UM3 EES (Olympus) & $7.5 \mathrm{MHz}$ \\
\hline Kida [27] & Japan & $\mathrm{NC}$ & 1551 & $\begin{array}{l}\text { (1) CEUS, (2) NCEUS, (3) UP, (4) 3D, XEU-IP automatic } \\
\text { mechanical spiral scanning }\end{array}$ & 12 and $20 \mathrm{MHz}$ \\
\hline Kim [28] & Korea & $\mathrm{R}$ & 206 & (1) GF-240 (Olympus), (2) GFUM-2000 (Olympus), (3) Miniprobe & 5-20 MHz \\
\hline Lee [29] & China & $\mathrm{P}$ & 241 & (1) GF-UM20 EES, (2) GF-UM240 EES & 7.5 and $12 \mathrm{MHz}$ \\
\hline Polkowski [30] & Poland & $\mathrm{P}$ & 88 & GF-UM20 radial EES (Olympus) & 7.5 and $12 \mathrm{MHz}$ \\
\hline Potrc [31] & Slovenia & $\mathrm{P}$ & 82 & EUM-20 radial technology ultrasound probe (Olympus) & 7.5 and $12 \mathrm{MHz}$ \\
\hline Shimoyama [32] & Japan & $\mathrm{R}$ & 45 & Endoscope with linear probe at the distal end & $7.5 \mathrm{MHz}$ \\
\hline Tan [33] & China & $\mathrm{NC}$ & 63 & $\begin{array}{l}\text { (1) GF-240 electronic gastroscope (Olympus), (2) GF-UMQ } 240 \\
\text { electro-ultrasonic gastroscope, } 360^{\circ} \text { circular scan (Olympus) }\end{array}$ & $7.5-20 \mathrm{MHz}$ \\
\hline Tsendsuren [34] & China & $\mathrm{NC}$ & 41 & $\begin{array}{l}\text { EG-3630U (Pentax), EUB-525 (Hitachi). EES with real-time } \\
\text { ultrasound imaging linear scanning transducers and Doppler }\end{array}$ & 5.0 and $7.5 \mathrm{MHz}$ \\
\hline Wang [35] & China & $\mathrm{P}$ & 119 & GF-UM3 radial sector scan transducer (Olympus) & 7.5 or $12 \mathrm{MHz}$ \\
\hline Willis [36] & Germany & $\mathrm{P}$ & 116 & GIF-UM20 radial scanning (Olympus) & 7.5-12 MHz \\
\hline $\mathrm{Xi}[37]$ & China & $\mathrm{NC}$ & 35 & Fujinon SP-701 radial scanning probes & $7.5,12$ and $20 \mathrm{MHz}$ \\
\hline
\end{tabular}

$P$ prospective, $R$ retrospective, $N C$ not clear/not sufficient details to determine, $N R$ not reported, $N$ number of patients, $C E U S$ conventional endoscopic ultrasound (EUS), NCEUS new conventional EUS, UP ultrasound probe, $3 D$ three-dimensional, EES echoendoscope

${ }^{a}$ More details not given

duplicates and screening for relevant titles and abstracts, 122 articles were submitted for a full review. A total of 22 were included [7, 17-37] (Fig. 1); the characteristics are presented in Table 1. A total of 2445 patients were staged preoperatively by EUS; the majority were from studies from Asia (1892 patients), followed by Europe (337 patients), and North America (216 patients). The majority of participants presented with T3 disease $(n=873)$, followed by T2 disease $(n=734)$, T1 disease $(n=584)$, and T4 disease $(n=254)$.

T stage

The diagnostic accuracy of EUS for overall $\mathrm{T}$ staging varied between 56.9 and $87.7 \%$ and the pooled accuracy was $75 \%(95 \%$ CI: 71-80\%) with a moderate pooled Kappa (0.52; 95\% CI: 0.38-0.67). For T1, individual study accuracy ranged from 14 to $100 \%$ and the pooled accuracy was $77 \%$ (95\% CI: 70-84\%) (Fig. 2). T2 staging accuracy ranged from 24 to $90 \%$ and the pooled accuracy was $65 \%$ (95\% CI: 57-73\%) (Fig. 3). Accuracy ranged from 50 to $100 \%$ for T3 staging and the pooled accuracy was $85 \%$ (95\% CI: 82-88\%) (Fig. 4). EUS accuracy for T4 staging ranged from 25 to $100 \%$ and the pooled accuracy was $79 \%$ (95\% CI: 68-90\%) (Fig. 5). The 95\% CIs for the pooled accuracies overlap in forest plots for all $\mathrm{T}$ stages, indicating that they are not statistically different from each other. The calculated $I^{2}$ value for all pooled accuracy estimates was 89.5\% (95\% CI: 85-92\%). The Cochran $Q$ test confirmed that the included studies were heterogeneous $(P<0.0001)$. 


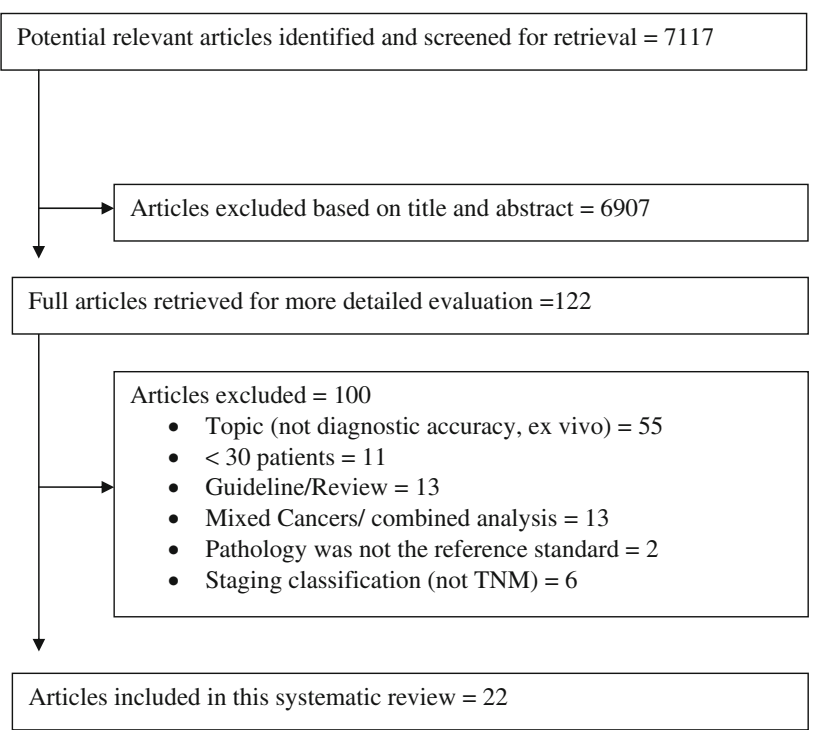

Fig. 1 Article selection flow

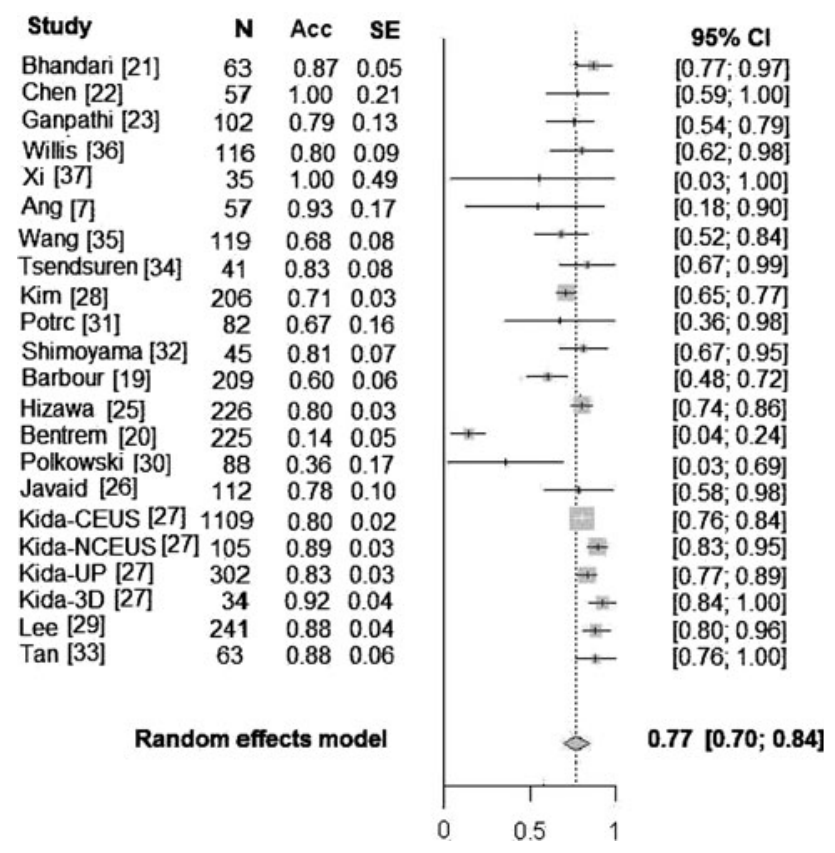

Fig. 2 EUS accuracy for T1 staging. $N$ Number of patients, Acc accuracy, $S E$ standarderror, $C I$ confidence interval, $C E U S$ conventional EUS, NCEUS new conventional EUS, $U P$ ultrasound probe, $3 D$ three-dimensional

\section{N stage}

EUS diagnostic accuracy for $\mathrm{N}$ staging ranged from 30 to 90\%; sensitivity ranged from 16.6 to $96.8 \%$; and specificity from 57.1 to $100 \%$. The pooled accuracy for $\mathrm{N}$ staging was 64\% (95\% CI: $43-84 \%$ ); the pooled sensitivity was $74 \%$ (95\% CI: $66-81 \%$ ); and the pooled specificity was $80 \%$ (95\% CI: 74-87\%) (Figs. 6, 7). The calculated $I^{2}$ values for

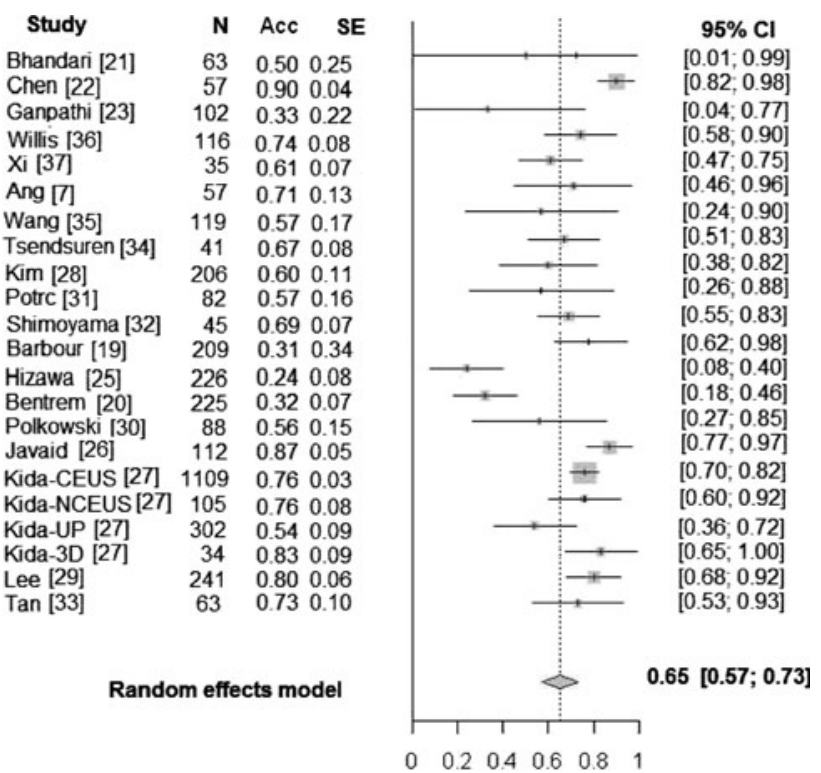

Fig. 3 EUS accuracy for T2 staging

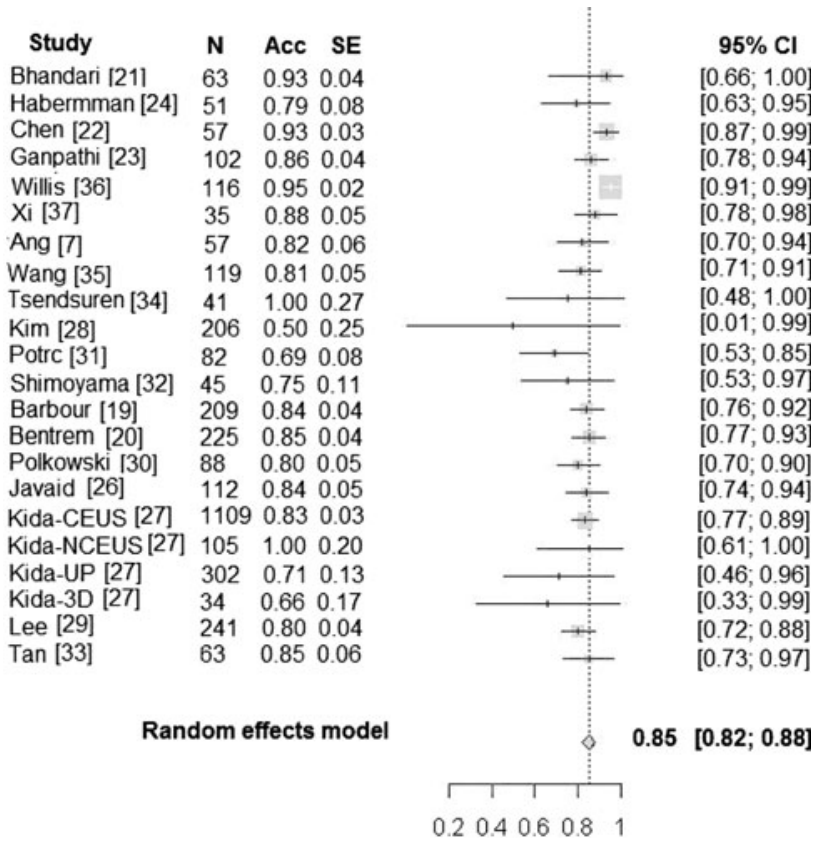

Fig. 4 EUS accuracy for T3 staging

pooled sensitivity and specificity were $I^{2}=89.9 \%(85.8 \%$; $92.9 \%)$ and $I^{2}=85.6 \%(78.8 \% ; 90.2 \%)$, respectively. The Cochran $Q$ test revealed that the studies included were heterogeneous $(P<0.0001)$.

Effect of annual volume

Subgroup analyses did not demonstrate an association between EUS performance in T and $\mathrm{N}$ staging and EUS annual volume $(P=0.836,0.99$, respectively). 


\begin{tabular}{|c|c|c|c|c|}
\hline Study & & & & $95 \%-\mathrm{Cl}$ \\
\hline Bhandari [21] & $\begin{array}{l}N \\
63\end{array}$ & $\begin{array}{l}\text { Acc } \\
1.00 \\
1.50\end{array}$ & & {$[0.03 ; 1.00]$} \\
\hline Habermman [24] & 51 & $1.00 \quad 0.29$ & & {$[0.29 ; 1.00]$} \\
\hline Chen [22] & 57 & $1.00 \quad 0.29$ & & {$[0.29 ; 1.00]$} \\
\hline Ganpathi [23] & 102 & $0.73 \quad 0.11$ & $\longrightarrow$ & {$[0.39 ; 0.94]$} \\
\hline Willis [36] & 116 & 0.830 .06 & & {$[0.61 ; 0.95]$} \\
\hline Xi [37] & 35 & $0.73 \quad 0.12$ & & {$[0.35 ; 0.97]$} \\
\hline Wang [35] & 119 & $0.53 \quad 0.23$ & & {$[0.01 ; 0.99]$} \\
\hline Tsendsuren [34] & 41 & 0.250 .29 & & {$[0.01 ; 0.81]$} \\
\hline Kim [28] & 206 & 1.000 .49 & & {$[0.03 ; 1.00]$} \\
\hline Potrc [31] & 82 & $0.60 \quad 0.18$ & & {$[0.15 ; 0.95]$} \\
\hline Polkowski [30] & 88 & $0.33 \quad 0.13$ & $\longrightarrow$ & {$[0.13 ; 0.59]$} \\
\hline Javaid [26] & 112 & 0.810 .10 & + & {$[0.83 ; 1.00]$} \\
\hline Lee [29] & 241 & $0.94 \quad 0.03$ & + & {$[0.83 ; 0.95]$} \\
\hline Tan [33] & 63 & 0.770 .11 & & {$[0.55 ; 0.99]$} \\
\hline \multirow{3}{*}{\multicolumn{3}{|c|}{ Random effects model }} & \multicolumn{2}{|r|}{$0.79[0.68 ; 0.90]$} \\
\hline & & & $T$ & 7 \\
\hline & & & 0.5 & 1.5 \\
\hline
\end{tabular}

Fig. 5 EUS accuracy for T4 staging

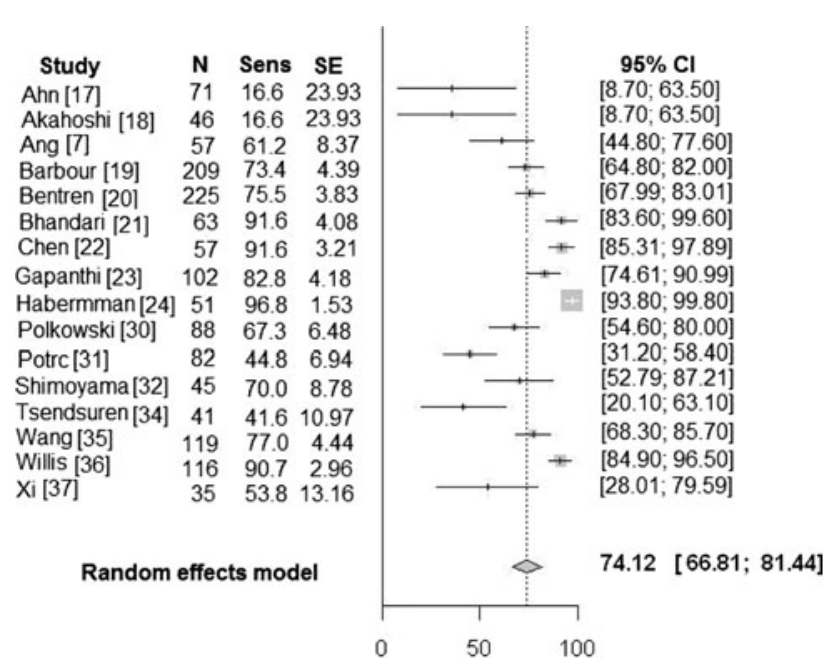

Fig. 6 EUS sensitivity for N staging. Sens sensitivity

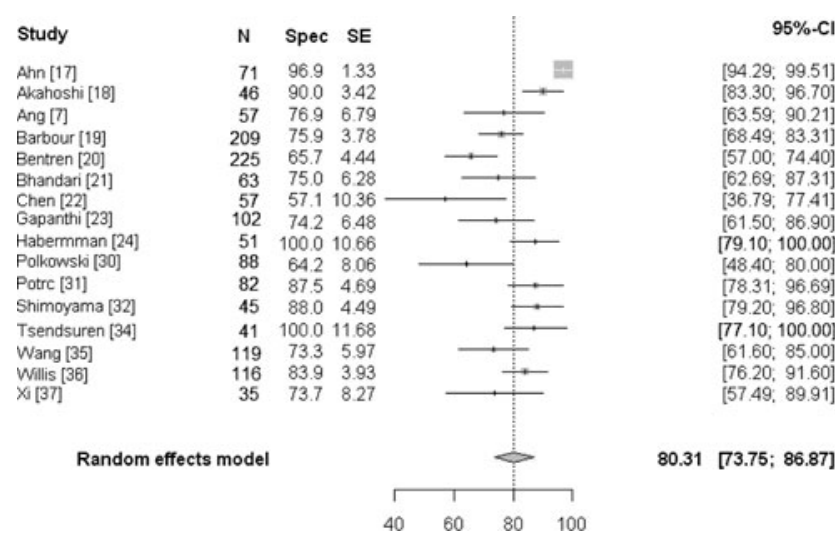

Fig. 7 EUS specificity for $\mathrm{N}$ staging. Spec specificity

\section{EUS examination}

Combinations of different transducer frequencies were used in the majority of the studies. Fifteen studies [7, 17, 19, 20, 22-24, 26, 29-32, 34-36] used combinations of frequencies of $\leq 12 \mathrm{MHz}$ and six studies [18, 25, 27, 28, $33,37]$ used combinations of frequencies ranging from 5 to $20 \mathrm{MHz}$. It was not feasible to construct a $2 \times 2$ table to investigate transducer frequencies as source of heterogeneity. However, based on the data from 13 studies $(\leq 12 \mathrm{MHz})$ it was possible to confirm that EUS staging accuracy varied vastly in the studies using low-frequency transducers. The accuracy of $\mathrm{T} 1$ staging varied from 40 to $100 \%$, T2 staging from 0 to $90 \%$, T3 staging from 54 to $100 \%$, and $\mathrm{T} 4$ staging from 0 to $100 \%$.

\section{Discussion}

Accurate staging influences management decisions and predicts prognosis for gastric cancer patients. It is utilized to select patients for endoscopic or laparoscopic treatment, for the selection of those who may benefit from less invasive diagnostic procedures [38], and for the selection of those who may benefit from multimodal treatment [39, 40]. However, it is operator-dependent, adds incremental costs, and has a risk of complications, including mortality. In the present meta-analysis of 22 studies, the pooled accuracy of EUS for tumor invasion (T stage) was moderate; however, it tended to be higher for advanced disease when compared to early disease. EUS tended to perform slightly worse for nodal staging, with moderate accuracy, sensitivity, and specificity. There was significant variability across studies resulting in statistical heterogeneity which was not explained by the annual volume of EUS procedures performed at an institution.

There are few other published systematic reviews and meta-analyses assessing EUS performance for staging gastric cancer. An early systematic review by Kelly et al. [5] evaluated 27 articles, published between 1981 and 1996, of which 13 evaluated gastric cancer, and found that EUS performed better for staging gastric carcinoma compared to carcinomas of the esophagus. As with the study by Kelly et al., we found that EUS performed better when staging tumor invasion than when staging nodal status. In addition, we found that EUS tended to be more accurate for the diagnosis of more advanced $\mathrm{T}$ stages (T3 and T4 disease). Our findings are consistent with a meta-analysis by Puli et al. [1], which evaluated 22 studies (1986-2006), and also described better EUS accuracy in higher T-stage disease.

In some of the other meta-analyses [6, 41], EUS staging performance for $\mathrm{T}$ and $\mathrm{N}$ stage was compared with that of 
other imaging modalities such as abdominal ultrasound (AUS), conventional MRI, and CT. While these reviews suggest that no modality consistently achieves both high sensitivity and high specificity in staging gastric cancer, our study did not compare EUS to other imaging modalities. Our group has performed a separate meta-analysis of radiologic imaging in the preoperative management of gastric cancer, finding an overall accuracy for $\mathrm{T}$ stage of 68,72 , and $83 \%$ and an overall accuracy for $\mathrm{N}$ stage of 68 , 66, and 53\% for AUS, CT, and MRI, respectively [42]. All meta-analyses of EUS in gastric cancer published to date have identified significant heterogeneity in the included studies. In our study and that reported by Kwee and Kwee [43] subgroup analyses were performed to try to identify the sources of heterogeneity. Kwee and Kwee [43] included 18 studies from 1988 to 2007 in their study and found that heterogeneity was eliminated if studies were restricted to those evaluating patients with early gastric cancer and those that used transducers with frequencies less than $15 \mathrm{MHz}$. Our review showed that EUS performance for $\mathrm{T}$ staging varied between studies using low-frequency transducers, but a comparison of accuracy for the high-frequency probes versus the low-frequency probes was not possible, as no studies exclusively used high-frequency probes. Kwee and Kwee [43] also examined the total number of patients in each study and the country of origin of the study, both of which factors might be reflective of operator experience, but they found that neither of these factors explained the heterogeneity. Similarly, we thought that operator experience, as measured by annual EUS volume, might explain the heterogeneity. However, we found no association between annual EUS volume and accuracy. Therefore, this factor cannot explain the heterogeneity.

There were a few limitations to our meta-analysis. The majority of included patients were staged preoperatively by EUS in Asia. Consequently, the reported results may not be generalizable to other, lower-volume regions. Also, the way in which individual studies reported their results affected their inclusion in the meta-analysis. For example, some studies reported results for $\mathrm{T}$ staging as $\mathrm{T} 1 / \mathrm{T} 2$ and $\mathrm{T} 3 / \mathrm{T} 4$, which precluded data extraction for $\mathrm{T}$ stage, although data on $\mathrm{N}$ staging ( $\mathrm{N} 0$ vs. $\mathrm{N}+$ ) could be extracted and analyzed. Lastly, our meta-analysis, like the others that have been previously published, demonstrated significant heterogeneity, with no clear explanation for this. As a result, caution must be used in interpreting the findings.

\section{Conclusion}

Our review found EUS to have only moderate agreement and accuracy for both $\mathrm{T}$ and $\mathrm{N}$ staging. EUS may be most useful for staging cancers with greater tumor involvement (T3 and T4). The significant heterogeneity of the included studies should be taken into consideration when interpreting our findings. The decision to use EUS, which has only moderate accuracy in the staging of gastric cancer, must be balanced against the predicted change in management, as other less invasive staging methods exist.

Acknowledgments This study was funded by the Canadian Cancer Society (grant \# 019325). Dr. Coburn is supported by a Ministry of Health and Long Term Care Career Scientist Award. Dr. Tinmouth is supported by a CIHR New Investigator Award. Dr. Law is supported by the Hanna Family Chair in Surgical Oncology.

\section{References}

1. Puli SR, Reddy JBK, Bechtold ML, Antillo MR. How good is endoscopic ultrasound for TNM staging of gastric cancer? A meta-analysis and systematic review. World J Gastroenterol. 2008;14(25):4011-9.

2. Scottish Intercollegiate Guidelines Network (SIGN). Management of oesophageal and gastric cancer. Edinburgh: Scottish Intercollegiate Guidelines Network; 2006. p. 74.

3. Maluf-Filho F, Dotti C, Halwan B, Queiros A, Kupski C, Chaves $\mathrm{D}$, et al. An evidence-based consensus statement on the role and application of endosonography in clinical practice. Endoscopy. 2009;41:979-87.

4. NCC Network. NCCN clinical practice guidelines in oncology: gastric cancer. National Comprehensive Network Website. 2011. p. 47. http://www.ncen.org/professionals/physician_gls/ pdf/gastric.pdf

5. Kelly S, Harris KM, Berry E, Hutton J, Roberik P, Cullingworth $\mathrm{J}$, et al. A systematic review of staging performance of endoscopic ultrasound in gastro-oesophageal carcinoma. Gut. 2001;49:534-9.

6. Kwee RM, Kwee TC. Imaging in local staging of gastric cancer: a systematic review. J Clin Oncol. 2007;15:2107-16.

7. Ang TL, Ng TM, Fock KM, Teo EK. Accuracy of endoscopic ultrasound staging of gastric cancer in routine clinical practice in Singapore. Chin J Dig Dis. 2006;7(4):191-6.

8. Takedo T, Yanai H, Tada M, et al. Application of ultrasonic probes prior to endoscopic resection of early gastric cancer. Endoscopy. 1992;24(Suppl 1):329-33.

9. Bergman JGHM, Fockens P. Endoscopic ultrasonography in patients with gastro-esophageal cancer. Eur $\mathrm{J}$ Ultrasound. 1999;10:127-38.

10. Pollack B, Chak A, Sivak MV. Endoscopic ultrasonography. Semin Oncol. 1996;23:336-46.

11. American Society for Gastrointestinal Endoscopy. Endoscopic ultrasound probes. Gastrointest Endosc. 2006;63(6):751-4.

12. Boutron I, Moher D, Altman DG, Schulz KF, Ravaud P. Extending the CONSORT statement to randomized trials of nonpharmacological treatment explanation and elaboration. Ann Intern Med. 2008;148:295-309.

13. Moher D, Simera I, Schulz KF, Hoey J, Altman DG. Helping editors, peer reviewers and authors improve the clarity, completeness and transparency of reporting health research. BMC Med. 2008;6:13.

14. Lai TY, Wong VW, Lam RF, Cheng AC, Lam DS, Leung GM. Quality of reporting of key methodological items of randomized controlled trials in clinical ophthalmic journals. Ophthalmic Epidemiol. 2007;14:390-8. 
15. Jadad A, Moore R, Carroll D, Jenkinson C, Reynolds D, Gavaghan $\mathrm{D}$, et al. Assessing the quality of reports of randomized clinical trials: is blinding necessary? Control Clin Trial. 1996;17:1-12.

16. Cantor A. Sample-size calculation for Cohen's kappa. Psychol Methods. 1996;1:150-3.

17. Ahn HS, Lee HJ, Yoo MW, Kim SG, Im JP, Kim SH, et al. Diagnostic accuracy of $\mathrm{T}$ and $\mathrm{N}$ stages with endoscopy, stomach protocol CT, and endoscopic ultrasonography in early gastric cancer. J Surg Oncol. 2009;99(1):20-7.

18. Akahoshi K, Chijiwa Y, Hamada S, Sasaki I, Nawata H, Kabemura $\mathrm{T}$, et al. Pretreatment staging of endoscopically early gastric cancer with a $15 \mathrm{MHz}$ ultrasound catheter probe. Gastrointest Endosc. 1998;48(5):470-6.

19. Barbour AP, Rizk NP, Gerdes H, Bains MS, Rusch VW, Brennan MF, et al. Endoscopic ultrasound predicts outcomes for patients with adenocarcinoma of the gastroesophageal junction. J Am Coll Surg. 2007;205(4):593-601.

20. Bentrem D, Gerdes H, Tang L, Brennan M, Coit D. Clinical correlation of endoscopic ultrasonography with pathologic stage and outcome in patients undergoing curative resection for gastric cancer. Ann Surg Oncol. 2007;14(6):1853-9.

21. Bhandari S, Shim CS, Kim JH, Jung IS, Cho JY, Lee JS, et al. Usefulness of three-dimensional, multidetector row CT (virtual gastroscopy and multiplanar reconstruction) in the evaluation of gastric cancer: a comparison with conventional endoscopy, EUS, and histopathology. Gastrointest Endosc. 2004;59(6): 619-26.

22. Chen $\mathrm{CH}$, Yang CC, Yeh YH. Preoperative staging of gastric cancer by endoscopic ultrasound: the prognostic usefulness of ascites detected by endoscopic ultrasound. J Clin Gastroenterol. 2002;35(4):321-7.

23. Ganpathi IS, So JB, Ho KY. Endoscopic ultrasonography for gastric cancer: does it influence treatment? Surg Endosc. 2006;20(4):559-62.

24. Habermann CR, Weis F, Riecken R, Honarpisheh H, Bohnacker S, Staedtler C, et al. Preoperative staging of gastric adenocarcinoma: comparison of helical CT and endoscopic US. Radiology. 2004;230(2):465-71.

25. Hizawa K, Iwai K, Esaki M, Matsumoto T, Suekane H, Iida M. Is endoscopic ultrasonography indispensable in assessing the appropriateness of endoscopic resection for gastric cancer? Endoscopy. 2002;34(12):973-8.

26. Javaid G, Shah OJ, Dar MA, Shah P, Wani NA, Zargar SA. Role of endoscopic ultrasonography in preoperative staging of gastric carcinoma. ANZ J Surg. 2004;74(3):108-11.

27. Kida M, Tanabe S, Watanabe M, Kokutou M, Kondou I, Yamada $\mathrm{Y}$, et al. Staging of gastric cancer with endoscopic ultrasonography and endoscopic mucosal resection. Endoscopy. 1998;30(Suppl 1):A64-8.

28. Kim JH, Song KS, Youn YH, Lee YC, Cheon JH, Song SY, et al. Clinicopathologic factors influence accurate endosonographic assessment for early gastric cancer. Gastrointest Endosc. 2007;66(5):901-8.

29. Lee YT, Ng EK, Hung LC, Chung SC, Ching JY, Chan WY, et al. Accuracy of endoscopic ultrasonography in diagnosing ascites and predicting peritoneal metastases in gastric cancer patients. Gut. 2005;54(11):1541-5.

30. Polkowski M, Palucki J, Wronska E, Szawlowski A, Nasierowska-Guttmejer A, Butruk E. Endosonography versus helical computed tomography for locoregional staging of gastric cancer. Endoscopy. 2004;36(7):617-23.

31. Potrc S, Skalicky M, Ivanecz A. Does endoscopic ultrasound staging already allow individual treatment regimens in gastric cancer. Wien Klin Wochenschr. 2006;118(Suppl 2):48-51.

32. Shimoyama S, Yasuda H, Hashimoto M, Tatsutomi Y, Aoki F, Mafune K, et al. Accuracy of linear-array EUS for preoperative staging of gastric cardia cancer. Gastrointest Endosc. 2004;60(1): $50-5$.

33. Tan SY, Wang JY, Shen L, Luo HS, Shen ZX. Relationship between preoperative staging by endoscopic ultrasonography and MMP-9 expression in gastric carcinoma. World J Gastroenterol. 2007;13(14):2108-12.

34. Tsendsuren T, Jun SM, Mian XH. Usefulness of endoscopic ultrasonography in preoperative TNM staging of gastric cancer. World J Gastroenterol. 2006;12(1):43-7.

35. Wang JY, Hsieh JS, Huang YS, Huang CJ, Hou MF, Huang TJ. Endoscopic ultrasonography for preoperative locoregional staging and assessment of resectability in gastric cancer. Clin Imaging. 1998;22(5):355-9.

36. Willis S, Truong S, Gribnitz S, Fass J, Schumpelick V. Endoscopic ultrasonography in the preoperative staging of gastric cancer: accuracy and impact on surgical therapy. Surg Endosc. 2000;14(10):951-4.

37. Xi WD, Zhao C, Ren GS. Endoscopic ultrasonography in preoperative staging of gastric cancer: determination of tumor invasion depth, nodal involvement and surgical resectability. World J Gastroenterol. 2003;9(2):254-7.

38. Polkowski M. Endosonographic staging of upper intestinal malignancy. Best Pract Res Clin Gastroenterol. 2009;23:649-61.

39. Orditura M, De Vita F, Muto P, Vitiello F, urino P, Lieto E, et al. Patients with stage III or IV radically resected gastric cancer. A pilot study. Arch Surg. 2010;145(3):233-8.

40. Benson AB. Advanced gastric cancer: an update and future directions. Gastrointest Cancer Res. 2008;2(4 suppl):S47-53.

41. Kwee R, Kwee T. Imaging in assessing lymph node status in gastric cancer. Gastric Cancer. 2009;12:6-22.

42. Seevaratnam R, Cardoso R, McGregor C, Lourenco L, Mahar A, Sutradhar R, et al. How useful is pre-operative imaging for tumor, node, metastasis ( $T, N, M)$ staging of gastric cancer? A metaanalysis. Gastric Cancer. 2011. doi:10.1007/s10120-011-0069-6

43. Kwee RM, Kwee TC. The accuracy of the endoscopic ultrasonography in differentiating mucosal from deeper gastric cancer. Am J Gastroenterol. 2008;103(7):1801-9. 